\title{
A disposable cannula for the aspiration of soft lens matter
}

\author{
A. J. LYNE \\ From the Department of Ophthalmology, Peterborough District Hospital, Peterborough
}

SUMMARY A double cannula is described suitable for the aspiration of soft lens matter. The cannula is a modification of a double irrigation needle already marketed and will be available in a presterilised disposable pack for use with disposable syringes.

Aspiration of lens matter (Scheie, 1960) is now generally accepted to be the method of choice when treating congenital cataracts as well as those in young adults when the nucleus is not sufficiently dense to cause problems. Many types of instrument have been devised for the operation. Many of them have been concerned with precise replacement of the volume of fluid aspirated in order to avoid loss of the anterior chamber (Fink and Weinstein, 1964; Atchoo, 1968; Phillips and Wang, 1971). With the use of the operating microscope equipped with an observer's viewing eyepiece and with the help of a competent assistant it is quite possible to maintain the depth of the anterior chamber throughout by syringing fluid gently into the anterior chamber with one syringe while at the same time aspirating fluid and lens matter with another (Ferguson, 1964; Girard, 1967; O'Gawa, 1967; Bruun-Jensen, 1969; Rice, 1977).

The purpose of this brief account is to describe a disposable double cannula, shortly to be available in prepacked and sterilised form, which can be used in conjunction with disposable syringes in everyday use.

The cannula is a modification of a disposable double cannula already available. It consists of a double pair of rounded off 'green' disposable needles, fused together, one needle being set back upon the other (Fig. 1). The longer of the 2 needles is attached to a disposable $2 \mathrm{ml}$ syringe by means of a Luer fitting. The shorter of the 2 needles is attached to a length of soft Silastic tubing, about 6 in $(15 \mathrm{~cm})$ long, which fits on to a straight blunted needle of the same gauge and via a Luer fitting to the second syringe.

It is possible to use a drip bottle attached directly to the shorter needle, but the latter is more bulky,

Address for reprints: Mr A. Lyne, Wyncroft, 149 Oundle Road, Orton Longueville, Peterborough PE2 ODH

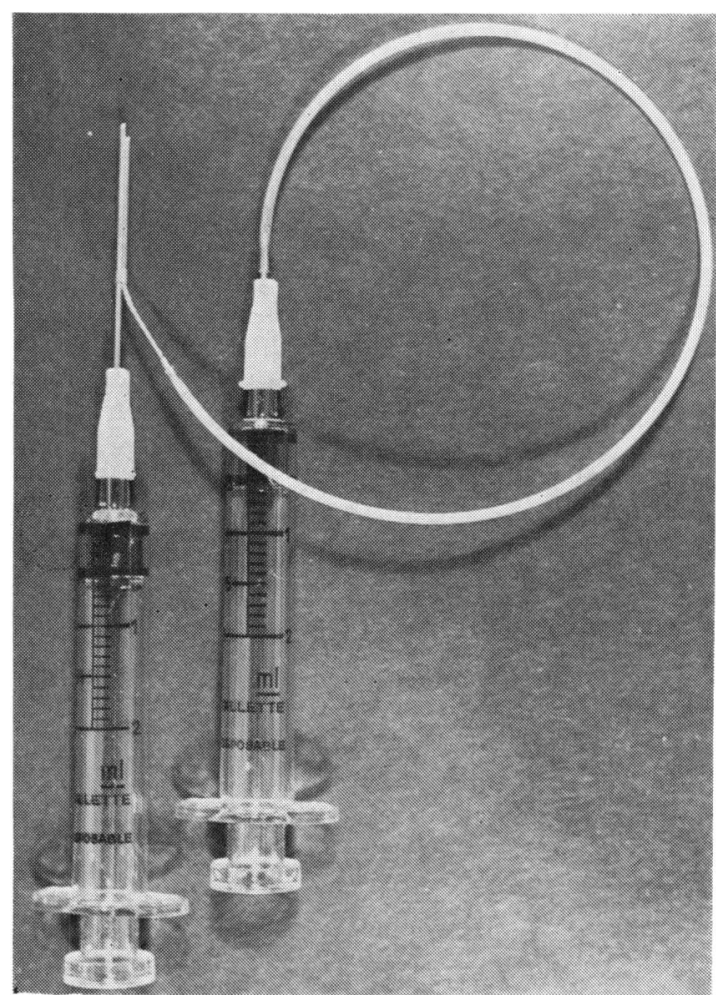

Fig. 1

and, the tubing being thicker, this tends to make delicate movements of the cannula within the eye more difficult. Maintaining sterility is also more difficult.

\section{Method}

The whole operation is performed through a single incision. The pupil is as widely dilated as possible, 
as for any aspiration procedure. An iridectomy is not necessary. A small incision about $2 \mathrm{~mm}$ long is made through the corneal side of the limbus at either the 12 o'clock position or temporally. It is important that this incision is not made too large lest fluid escape around the cannula and maintainance of the anterior chamber be difficult. If desired a U suture as described by Worst (1964) can be employed, but slight leakage is advantageous in preventing excessive inflow pressure. A disposable needle which has been 'hooked' at its point is passed into the anterior chamber and incises the anterior capsule. This needle is removed and the double needle inserted. Lens matter is gently aspirated while the assistant maintains the depth of the anterior chamber by observing through the assistant's eyepiece and using the inflow syringe.

Lens matter is aspirated quite quickly, the only difficult area being the equator of the lens beneath the cannula, but this can usually be dealt with as the cannula is withdrawn. The incision does not usually need to be sutured. Opinion is divided on the merits of using separate cannulae with 2 small incisions into the eye or a double cannula with a single slightly larger incision. The larger incision usually heals without complication, and a buried 10.0 monofilament nylon suture can be employed if necessary. Control of the input cannula in the former arrangement can be troublesome, because it is often just outside the microscope field and it is also liable to come out of the eye, especially if fine-bore tubing is used (Rice, 1977). For these reasons the double cannula described would seem to be the simplest and most convenient of the arrangements so far employed.

Messrs Needle Industries of Redditch made the cannula available.

\section{References}

Atchoo, P. D. (1968). Double barrel anterior chamber irrigating needle. Archives of Ophthalmology, 79, 580-581.

Bruun-Jensen, J. (1969). Cataract aspiration-irrigation with twin needle. Acta Ophthalmologia, 47, 498-501.

Ferguson, E. C. (1964). A modified instrument for aspiration and irrigation of congenital of soft cataracts. American Journal of Ophthalmology, 27, 596-599.

Fink, A. I., and Weinstein, G. W. (1964). A modification of the Fuch's syringe. American Journal of Ophthalmology, 58, 129-130.

Girard, L. J. (1967). Aspiration-irrigation of congenital and traumatic cataracts. Archives of Ophthalmology, 77, 387391.

O'Gawa, G. M. (1967). Double-bore cataract aspiration needle. American Journal of Ophthalmology, 64, 970-971.

Phillips, C. I., and Wang, M. K. (1971). Cataract aspirationirrigation. British Journal of Ophthalmology, 55, 361-367.

Rice, N. S. C. (1977). Lens aspiration. Transactions of the Ophthalmological Societies of the United Kingdom, 97, 48-51.

Scheie, H. (1960). Aspiration of congenital or soft cataracts: A new technique. American Journal of Ophthalmology, 50, 1048-1055.

Worst, J. G. F. (1964). Goniotomy. American Journal of Ophthalmology, 57, 185-200. 